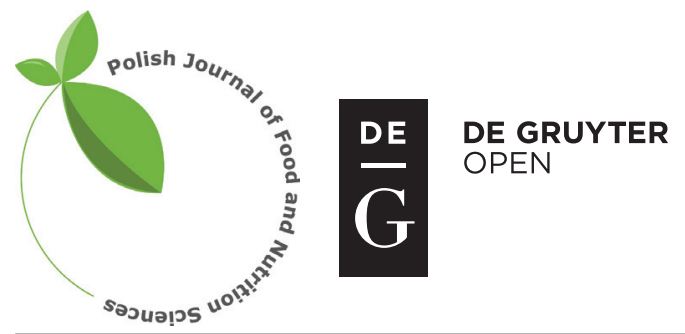

Pol. J. Food Nutr. Sci., 2016, Vol. 66, No. 3, pp. 211-219

10.1515/pjfns-2015-0033

Original article

Section: Food Quality and Functionality

\title{
Nutritional Value and Consumer Acceptance of New Cereal Bars Offered to Children
}

\author{
Matgorzata Biatek*, Jarostawa Rutkowska, Justyna Radomska
}

\author{
Department of Instrumental Analyses, Faculty of Human Nutrition and Consumer Sciences, \\ Warsaw University of Life Sciences, Nowoursynowska Str. 159c, 02-787 Warsaw, Poland
}

Key words: new product development, consumer preferences, school children, snack bar

\begin{abstract}
The main aim of this study was to determine consumer preferences by school-aged children and selected quality indicators of new, highly nutritive grain bars designed as a snack during school break. Consumer acceptance was evaluated by the scaling method using a five-point mimic hedonic scale. Triacylglycerols (TAG) and fatty acids (FA) composition was assayed in fats extracted from the designed bars (fresh and stored) by gas chromatography. Contents of oxidation and hydrolysis products were determined using peroxide value (PV), anisidine value (AnV), and acidic value (AV). The antioxidant activity of the ethanolic extract from bars was measured by scavenging 1,1-diphenyl-2-picrylhydrazyl (DPPH) radicals and Folin-Ciocalteau methods. The overall liking of bars was high (4.05 pts on average in the 5-point scale). The majority of children (71\%) scored the designed bars as tasty and very tasty. The designed products contained $22.3 \%$ of fat with about $44 \mathrm{~g} / 100 \mathrm{~g}$ FA of valuable fatty acids, e.g., short-chain saturated fatty acids (SCSFA), monounsaturated fatty acids (MUFA) and odd and branched chain fatty acids (OBCFA), recommended for young organisms. The content of CN52, CN54, CN50 and CN46 triacylglycerols (TAGs) (about $49 \mathrm{~g} / 100 \mathrm{~g} \mathrm{TAG)} \mathrm{was} \mathrm{due} \mathrm{to} \mathrm{both} \mathrm{milk} \mathrm{and} \mathrm{cocoa} \mathrm{fat.} \mathrm{Storage} \mathrm{of} \mathrm{bars} \mathrm{did} \mathrm{not} \mathrm{influence}$ their content of oxidation and hydrolysis products, resulting from a substantial content of total phenolics (TPC) (53.64 mg GAE/100 mL of extract) and DPPH scavenging activity at the level of $24 \%$. The designed bars may be an interesting confectionery product for children and an alternative to snacks currently available in school shops.
\end{abstract}

\section{INTRODUCTION}

Childhood obesity has become a serious public health problem in recent decades and is associated with severe health disorders and risk of illness [de Onis et al., 2010]. Already in 1997, the World Health Organization (WHO) has announced obesity as one of the most severe hazards to the health of children and adults [WHO Report, 1997]. The epidemiological and statistical data indicated that obesity among children had increased dramatically over the last two decades. In 2002, in the United States the problem of obesity affected as many as $30 \%$ of the surveyed children and adolescents [Hedley et al., 2004]. Haslam and James estimated that in $2005 \mathrm{ca}$. $10 \%$ of the global population under the age of 18 years has suffered from overweight or obesity [Haslam \& James, 2005]. In 2010, 43 millions of children were estimated to be overweight and obese; whereas 92 millions were at risk of overweight. This growing trend is expected to reach $9.1 \%$ in 2020 [de Onis et al., 2010].

According to estimates from the WHO's Childhood Obesity Surveillance Initiative (COSI), in the EU around 1 in 3 children aged 6-9 years were overweight or obese in 2010 [WHO Report, 2010]. A school-based survey conducted in 2010 among 10-12 year old children in seven Euro-

\footnotetext{
* Corresponding Author: Tel.: 4822 5937081; Fax: 4822 5937071;

E-mail: malgorzata_bialek@sggw.pl (M. Białek)
}

pean countries revealed that $25.8 \%$ of boys and $21.8 \%$ of girls were overweight (including obese) [Brug et al., 2012].

Increases in obesity levels have been observed even in very young preschool children, which is very alarming [Lakshman et al., 2012]. A current survey in the USA has reported that among children who became obese between the ages of 5 and 14 years, nearly half had been overweight and $75 \%$ had been above the 70th percentile for body mass index at the baseline [Cunningham et al., 2014].

Also in Poland the problem of obesity among children and adolescents under 18 years of age has escalated within the last 10-15 years. Cyclic surveys conducted by the Institute of Mother and Child in Warsaw have demonstrated that the problem of obesity affects $18.3 \%$ whereas the problem of overweight $-3.4 \%$ of children aged 11-12- years [WHO Report from 2009/2010]. The incidence of obesity in Polish children varies depending on their age and region of residence [Sikorska-Wiśniewska, 2007]. The degree of overweight and obesity among 7-9 year old children in different regions of Poland was shown to vary. The highest incidence of overweight and obesity was found in the Masovian province and the lowest in the Subcarpathian province [Wolnicka et al., 2012]. The latest research demonstrated that the average incidence of obesity among Polish children accounts for 17\% [UNICEF Report, 2013].

Among many dietary factors which facilitate the development of overweight and obesity in children, significant 
is the intake of highly-processed foods, with poor nutritional value but providing a high energy value, e.g. fast foods, chips, carbonated beverages, and sweets [Elliott et al., 2004]. While staying at school, adolescents willingly buy food products offered by school shops which, however, do not cover the daily demand for nutrients. According to Wojtyła-Buciora et al. [2013], the school children consumed definitely too frequently sweets and sweet beverages - 74\%, and salty snacks - $48 \%$ purchased at school shops. These products suppress the sensation of hunger, but have a high energy value from carbohydrates and saturated fats.

From the nutritional point of view, most cookies and confectionery products available on the market are not recommended for children. However, children constitute a significant group of confectionery products consumers owing to sensory attractiveness of these products and to heavy exposure to sweets advertising. For these reasons, children often consume excessive amounts of advertised confectionery products like, e.g., snack bars that are characterized by both a high energy value and a significant content of monosaccharides as well as low contents of dietary fiber and protein [Elliott, 2008]. These products are also substantial sources of fat which is associated with the presence of saturated fatty acids (SFA) and trans fatty acids (TFA). These compounds are responsible for an increasing level of plasma cholesterol, mainly LDL-cholesterol which is implicated in increasing the risk of development of cardiovascular diseases and type II diabetes [Mozaffarian et al., 2009].

Considering nutritional demands of children and development of appropriate eating habits, children need to be provided "snacks" that apart from taste values would also be sources of: high-quality protein, dietary fiber, easilydigestible fat and other valuable components. Whole grains and berries are recommended for young organisms as an important part of diet, because of their high nutritional value and health benefits [Holmer et al., 2012]. Oat is appropriate for bars enrichment due to considerable content of dietary fiber, especially its soluble fraction, with a predominating contribution of $\beta$-glucans having special physiological effects. $\beta$-Glucans are implicated in reducing the risk of colon cancer and glucose absorption in the digestive system. In addition, they play an important role in the prevention and treatment of gastrointestinal diseases and reduce blood level of cholesterol. They are also known for their immunomodulating properties [Wood, 2007]. Amaranth is a valuable ingredient in food production due to its unique protein composition with regard to quality and quantity. Processed products of amaranth, including seeds, flour, flakes and popped (expanded) seeds, are characterized by a high content of protein (especially high content of lysine being indispensable for developing organisms). Protein contained in amaranth seeds is characterized by high bioavailability [Mlakar et al., 2009]. In turn, chokeberry fruits are the richest source of polyphenolic compounds - natural antioxidants, which strengthen and seal blood vessels, prevent atherosclerotic lesions, as well as reduce blood pressure and the risk of cardiovascular diseases incidence. In addition, they exhibit anti-inflammatory, antiviral and antimycotic actions [Ferrazzano et al., 2011]. Milk fat is highly recommended for young organisms because
TABLE 1. Formulation of bars ( $\mathrm{g} / 100 \mathrm{~g}$ of product).

\begin{tabular}{|c|c|c|}
\hline \multirow{2}{*}{ Ingredient } & \multicolumn{2}{|c|}{ Type of bar } \\
\hline & TS & RS \\
\hline \multicolumn{3}{|c|}{ Bar base } \\
\hline Oat flakes (g) & 7.3 & 7.3 \\
\hline Popped amaranth seeds (g) & 3.8 & 3.8 \\
\hline Apple juice (ml) & 10.0 & 10.0 \\
\hline Butter (g) & 6.4 & 6.4 \\
\hline Wheat flour (g) & 9.0 & 15.1 \\
\hline Cane sugar (g) & 6.1 & 0 \\
\hline Dehydrated chokeberry fruits (g) & 3.4 & 3.4 \\
\hline Vanilla sugar (g) & 2.0 & 2.0 \\
\hline Eggs (g) & 6.4 & 6.4 \\
\hline Baking powder (g) & 0.2 & 0.2 \\
\hline \multicolumn{3}{|c|}{ Filling } \\
\hline Milk $3.2 \%$ fat $(\mathrm{mL})$ & 6.4 & 6.4 \\
\hline Butter (g) & 13.9 & 13.9 \\
\hline Defatted powdered milk (g) & 8.5 & 11.9 \\
\hline Sugar (g) & 3.4 & 0 \\
\hline \multicolumn{3}{|c|}{ Assembly } \\
\hline Dark chocolate (g) & 8.5 & 8.5 \\
\hline Milk $3.2 \%$ fat (ml) & 4.3 & 4.3 \\
\hline Waffer cake (g) & 0.4 & 0.4 \\
\hline
\end{tabular}

TS = bar with typical saccharose content; RS = bar with reduced saccharose content

of its fatty acids (FAs) profile, especially nutritionally valuable short chain saturated fatty acids (SCSFA) and other bioactive compounds (proteins, peptides and oligosaccharides) [Mills et al., 2011].

The main aim of this study was to determine consumer preferences by school-aged children and selected quality indicators of new, highly nutritive grain bars designed as snack during a school break.

\section{MATERIALS AND METHODS}

\section{Preparation of grain bars}

The experimental material included snack bars characterized by an increased nutritional value and produced in two variants: with typical (TS) and with reduced (RS) content of saccharose. The increased nutritional value of designed bars resulted from the presence of highly nutritive ingredients, e.g. oat flakes, popped amaranth seeds, dehydrated chokeberries and butter. Detailed formulation of both variants of bars was presented in Table 1. The ingredients used for bars production were obtained from the local market.

Ingredients of snack bar base (eggs, butter, apple juice) were mixed with a mixer (type HR 7677/A, Phillips, Austria), poured into premixed dry ingredients and kneaded by hand. The resultant mixture was put into a baking tray as a flat square cake, baked at $200^{\circ} \mathrm{C}$ for $20 \mathrm{~min}$ in a convection oven with forced air circulation (Electrolux AR 85, Italy), and cooled at room temperature. All ingredients of the filing 
were mixed for 15 min into a smooth mixture. Glaze was prepared by slowly mixing the melted dark chocolate with milk at a temperature of about $40^{\circ} \mathrm{C}$ to obtain a uniform, smooth and shiny mass.

The bars were formed as follows: the cooled cereal cake was transferred onto a wafer cake coated with the milk filling, and pressed. The top layer of the cereal cake was poured with chocolate glazing and left to harden. Afterwards, the cake was cut into snack bars $3.5 \mathrm{~cm}$ in length and $2 \mathrm{~cm}$ in width. Products packed in bags made of polyethylene foil were stored for 4 months at a temp. of $10^{\circ} \mathrm{C}$.

\section{Evaluation of consumer acceptance by children}

The acceptability of bars was evaluated by potential consumers of the product - 162 children aged 7-12 years, from two schools located in the Mazowieckie Province. All participants were required to have parental consent. Testing was done during morning lessons in the classroom. All children were given a short training to familiarize them with testing procedure. The testing was conducted with the scaling method. Using a five-point mimic hedonic scale, the children expressed the degree of liking of the product by ticking the facial expression corresponding to their preferences. The degree of scale development was consistent with perception capabilities of children aged 7-12 years [Baryłko-Pikielna \& Matuszewska, 2014]. The samples were coded and served to the children at random to avoid any bias. Hedonic ratings of each bar were converted into a numeric score ranging from 1 - very untasty to 5 - very tasty. The results were obtained by calculation of overall mean and the acceptance index was determined as acceptance percentage considering 100\% the score 5 .

\section{Fat content determination}

From the designed snack bars (fresh and stored), fat was extracted with the Weibull-Stoldt method [Polish Standard PN-71/A-88021:1971P], which is a modification of the Soxhlet's method. The weighted portion of a snack bar was disintegrated, then hot water was added and the mixture was treated with hydrochloric acid to hydrolyze proteins and carbohydrates contained in the product. Once fat was separated from the hydrolysate, it was extracted with hexane, which was evaporated afterwards.

\section{Triacylglycerols (TAGs) composition analysis}

The separation of TAGs was conducted with gas chromatography technique according to Stołyhwo \& Rutkowska [2013] using an HP-Agilent 6890 apparatus, equipped in a capillary column $(30 \mathrm{~m} \times 0.25 \mathrm{~mm})$ with medium-polar stationary phase. A sample of fat $(0.15 \%$ in isooctane) was injected with the "cool on column" method. During analysis, the column's temperature was controlled according to the earlier fixed program: initial temperature $77^{\circ} \mathrm{C}$ for $3 \mathrm{~min}$, increase by $20^{\circ} \mathrm{C} / \mathrm{min}$ to $240^{\circ} \mathrm{C}$, and another increase by $3^{\circ} \mathrm{C} / \mathrm{min}$ to $345^{\circ} \mathrm{C}$. The total time of analysis reached $70 \mathrm{~min}$. Peaks were identified using a milk fat standard BCR 519 (Belgium). The quantitative analysis of TAGs in the analyzed sample of fat extracted from snack bars was conducted with the method of internal standardization, using correction factors (Response Factors).

\section{Fatty acid (FA) composition analysis}

Methyl esters of fatty acids (FAME) were prepared according to AOAC Official Method 963.22 [AOAC-IUPAC, 2000]. The analysis of FAME profile of fat substance extracted from snack bar was conducted with gas chromatography (GC) technique acc. to the Polish Standard [PN-EN ISO 5508:2000], using an HP-Agilent 6890N apparatus. Use was made of a column with highly polar stationary phase Rtx 2330 (length 100 m, 0.25 mm ID, $0.2 \mu \mathrm{m}$ Th.) (Restek Corp. USA). FAs were identified with the use of Supelco 37 standard No:47885-U (Sigma Aldrich). Detailed description of this method is described by Rutkowska et al. [2012].

\section{Calculation of nutritional value}

The nutritional value of the designed snack bars was calculated based on literature data: "Food Composition and Nutritional Value Tables" [Kunachowicz et al., 2005] and "DIETETYK" software (2001). To compare the nutritional value of the designed bars with commercial products, analyses were also conducted for the assortment of snack bars available at retail shops in schools of the surveyed children.

\section{Determination of fat oxidation and hydrolysis products content}

The fat fraction was analyzed in terms of health safety by determining contents of primary and secondary products of lipids oxidation. All analyses were conducted in triplicate. Determination of peroxides content was conducted according to ISO 3960:2012 standard method by assaying the peroxide value (PV) with the titration method. Results were expressed as meq $\mathrm{O} / \mathrm{kg}$ of fat. The content of secondary products of oxidation was determined with the spectrophotometric technique at $350 \mathrm{~nm}$ acc. to ISO 6885:2008 standard method by assaying the anisidine value $(\mathrm{AnV})$. Contents of free fatty acids (FFAs) were determined with the ISO 660:2010 standard method by assaying the acidic value (AV) to determine the content of products of the hydrolytic degradation of fat. Results were expressed as $\mathrm{mg} \mathrm{KOH} / \mathrm{g}$ of fat.

\section{Preparation of ethanolic extracts of bars}

Bars were powdered in a mortar. Then, $5 \mathrm{~g}$ of powder were mixed with $50 \mathrm{~mL}$ of ethanol/water $(80 / 20, \mathrm{v} / \mathrm{v})$ and the mixture was shaken at room temperature for $1 \mathrm{~h}$, and left overnight. The extract was separated by filtering through a filter paper (POCH, S.A., Gliwice, Poland), and the procedure was repeated twice with $50 \mathrm{~mL}$ of the solvent. The extract obtained was used for determinations of total phenolics content and DPPH (1,1-diphenyl-2-picrylhydrazyl radicals) scavenging activity.

\section{Determination of total phenolics content (TPC)}

Total phenolics content was determined spectrophotometrically by using Folin-Ciocalteu reagent [Singleton \& Rossi, 1965]. Gallic acid was used as a standard and results were expressed as gallic acid equivalents (GAE) (mg GAE/100 g of extract). The $0.1 \mathrm{~mL}$ ethanolic extract of bar was diluted with $7.9 \mathrm{~mL}$ of pure water. Folin-Ciocalteu's reagent $(0.5 \mathrm{~mL})$ and sodium carbonate solution $(1.5 \mathrm{~mL}$; concentration $20 \mathrm{~g} / 100 \mathrm{~mL}$ ) were added, and the reaction mixture was mixed 
thoroughly. The mixture was allowed to stand for $120 \mathrm{~min}$ with intermittent shaking, and absorbance was measured at $725 \mathrm{~nm}$ (Specord 40, Analytik Jena AG, Jena, Germany).

\section{Antioxidant activity determination}

Radical scavenging effect of the ethanolic extract of bars on 1,1-diphenyl-2-picrylhydrazyl radicals (DPPH) was determined according to the modified method of Sanchez-Moreno et al. [1998] with the modification consisting in the use of an ethanolic solution of DPPH (Sigma-Aldrich, $0.025 \mathrm{~g} / 1000 \mathrm{~mL}$ $96 \%$ ethanol). An aliquot (1.0 mL) of the DPPH solution was diluted in $2.9 \mathrm{~mL}$ of methanol, and $0.1 \mathrm{~mL}$ of the ethanolic extract of bars was added. The mixture was shaken vigorously and left to stand for $10 \mathrm{~min}$ in the dark, then the absorbance was measured at $515 \mathrm{~nm}$ (Specord 40, Analytik Jena AG, Jena, Germany) against the blank (mixture without extract). The antioxidative activity of the extracts was expressed as the percentage of quenched DPPH radical after incubation with the analyzed sample against a blank sample. The percentage of quenched DPPH radical was calculated from the following formula:

$$
\mathrm{DPPH}^{\cdot}=\left(\mathrm{A}_{\mathrm{DPPH}}-\mathrm{A}_{\mathrm{t}}\right) / \mathrm{A}_{\mathrm{DPPH}} \times 100(\%)
$$

where: $A_{D P P H}$ - absorbance of blank sample, $A_{t}$ - absorbance of the analyzed sample.

\section{Statistical analysis}

All chemical analyses were conducted in triplicate. Results (mean $\pm \mathrm{SD}$ ) were subjected to the analysis of variance (ANOVA) at a significance level of $\mathrm{P} \leq 0.05$ using STASTISTICA 9.1PL software (StatSoft, Inc. (2010)).

\section{RESULTS}

\section{Consumer evaluation by children}

The sensory evaluation demonstrated that the designed product received high scores by school-aged children. However, a slightly higher average score (4.21 pts.) was given to the TS variant, whereas the average score for the RS variant reached 3.89 pts. (Figure 1).

The study showed a significant effect of age on snack bar evaluation depending on saccharose content. The highest acceptability of the TS snack bar was noted in the group of children aged 8 years, whereas the designed RS snack bar content received the highest scores by children at the age of 9 years (Figure 1).

In the case of both variants of the designed snack bars, the majority of children evaluated them as "very tasty" and "tasty" (53.6\% and $21.8 \%$ in the case of TS bars, and $42.3 \%$ and $23.0 \%$ respectively in the case of RS bars) (Figure 2).

\section{Fat content and fat composition}

The mean fat content in the designed snack bars was $22.3 \pm 1.1 \%$. Gas chromatography enabled separations of 16 triacylglycerols (TAGs) and cholesterol in extracted fats from bars: CN 24 to $\mathrm{CN} 54$ (Table 2) in which the CN52, $\mathrm{CN} 54, \mathrm{CN} 50, \mathrm{CN} 46$ were predominating.

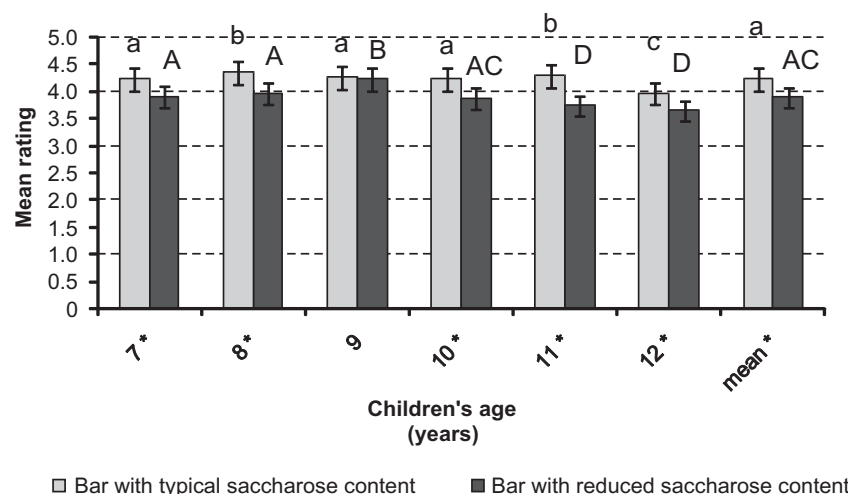

FIGURE 1. Mean rates of designed bars according to children's age. $\mathrm{A}, \mathrm{a}$ - significant $(\mathrm{p} \leq 0.05)$ differences according to saccharose content; *- significant $(\mathrm{p} \leq 0.05)$ differences according to children's age.

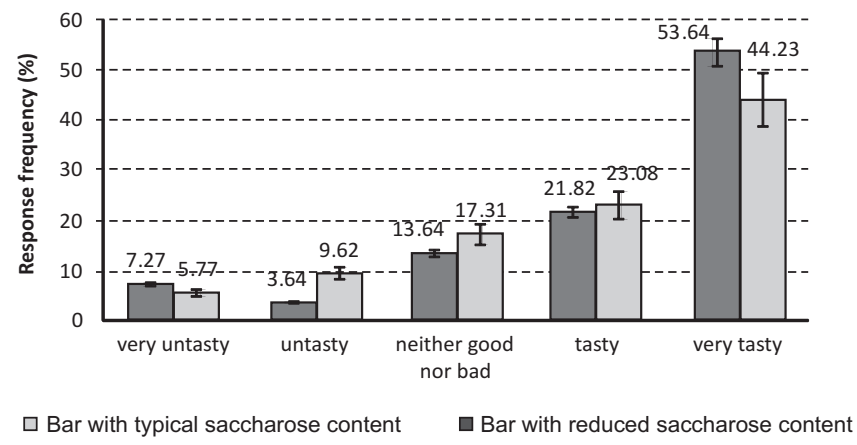

FIGURE 2. Distribution of individual preferences of two types of bars.

Results of FA profile analysis of fats extracted from experimental bars are presented in Table 3. The assayed FAs were classified into the following groups: saturated fatty acids (SFA) that were divided into short-chain saturated FA (SCSFA) and long-chain saturated FA (LCSFA) due to their different nutritional properties, monounsaturated FA (MUFA), polyunsaturated FA (PUFA) and odd- and branched chain FA (OBCFA). Quantitatively predominating groups were LCSFA and MUFA ( $50.55 \mathrm{~g} / 100 \mathrm{~g}$ FA and $25.33 \mathrm{~g} / 100 \mathrm{~g}$ FA on average, respectively). Noteworthy is also a significant content of SCSFA (14.03 g/100 g FA on average). Fats extracted from bars contained also FAs belonging to odd and branched chain fatty acids (OBCFA) (4.62 g/100 g FA on average) group. In fat extracted from bars, there were also assayed: isomer 9-cis 11-trans C18:2 (CLA - conjugated linoleic acid) $(0.31 \mathrm{~g} / 100 \mathrm{~g} \mathrm{FA}$ ) and isomer 11-trans C18:1 (VA - vaccenic acid) $(0.98 \mathrm{~g} / 100 \mathrm{~g} \mathrm{FA})$.

\section{Comparison of the nutritional value of experimental bars and snack bars available in school shops}

Table 4 presents the nutritional value of two variants of the designed snack bars and of commercial products offered in school shops $(n=13)$. The commercial products had energy value between 400 and $552 \mathrm{kcal} / 100 \mathrm{~g}$ of product, whereas the designed products were characterized by the following energy value: $410 \mathrm{kcal} / 100 \mathrm{~g}$ of product for TS and $390 \mathrm{kcal} / 100 \mathrm{~g}$ of product for RS. Considering simple sugars, their content was lower by $c a$. $40 \%$ in both variants 
TABLE 2. Composition of triacyloglycerols in fat extracted from designed bars (mean $\pm \mathrm{SD})$.

\begin{tabular}{l|c|c|c}
\hline \multirow{2}{*}{ TAG } & \multicolumn{3}{|c}{ Mean TAG content $(\mathrm{g} / 100 \mathrm{~g})$} \\
\cline { 2 - 4 } CN24 & Fresh ${ }^{\mathrm{a}}$ & Stored & $p \leq 0.05$ \\
CN26 & $0.14 \pm 0.05$ & $0.17 \pm 0.02$ & $*$ \\
Cholesterol & $0.30 \pm 0.08$ & $0.34 \pm 0.14$ & \\
CN28 & $0.31 \pm 0.03$ & $0.33 \pm 0.07$ & \\
CN30 & $0,59 \pm 0.11$ & $0.69 \pm 0.15$ & \\
CN32 & $0.93 \pm 0.09$ & $0.90 \pm 0.12$ & \\
CN34 & $1.92 \pm 0.35$ & $1.89 \pm 0.18$ & \\
CN36 & $4.74 \pm 0.21$ & $4.46 \pm 0.20$ & $*$ \\
CN38 & $8.82 \pm 0.41$ & $8.32 \pm 0.37$ & $*$ \\
CN40 & $9.62 \pm 0.19$ & $9.25 \pm 0.21$ & $*$ \\
CN42 & $7.27 \pm 0.07$ & $6.91 \pm 0.15$ & \\
CN44 & $5.32 \pm 0.11$ & $4.97 \pm 0.18$ & \\
CN46 & $5.07 \pm 0.21$ & $4.98 \pm 0.19$ & \\
CN48 & $5.75 \pm 0.17$ & $5.22 \pm 0.27$ & \\
CN50 & $7.22 \pm 0.28$ & $6.85 \pm 0.26$ & \\
CN52 & $12.23 \pm 0.35$ & $12.16 \pm 0.28$ & \\
CN54 & $17.80 \pm 0.29$ & $18.56 \pm 0.35$ & \\
\hline
\end{tabular}

a Values are expressed as mean \pm SD of results obtained for bar with typical (TS) and reduced (RS) saccharose content. Values with asterisk significantly differ $(p \leq 0.05)$. TAG $=$ triacylglycerol; $\mathrm{CN}=$ carbon number.

of the designed bars than in the commercial products. In most cases, the commercial products did not contain dietary fiber.

\section{Content of fat oxidation and hydrolysis products}

Results of the hydrolytic and oxidative changes in bars during storage are presented in Table 5. The AV informing about the content of FFAs reached $c a$. $7.27 \mathrm{mg} \mathrm{KOH} / \mathrm{g}$ fat on average and did not change over the storage period. The PV indicating the content of primary products of oxidation was low and did not exceed $2 \mathrm{mg}$ meqO $/ \mathrm{kg}$ fat and remained unchanged during storage. The content of secondary oxidation products, indicated by the $\mathrm{AnV}$, increased negligibly during storage (7.51 for fresh products and 7.82 for stored products).

\section{Total phenolics content and antioxidant activity}

Total phenolics content in designed bars was on average $53.64 \mathrm{mg} \mathrm{GAE} / 100 \mathrm{~mL}$ of extract (Table 5) and did not differ significantly among bar types. Also DPPH-scavenging activity of the ethanolic extract from designed bars was almost equal for each type of bar (about 24\%). The time of storage did not affect phenolics content nor DPPH of bars (Table 5).

\section{DISCUSSION}

A rapid increase has been observed in the incidence of overweight and obesity in children and adolescents. It may be presumed that the majority of obese adults were overweight or obese in their early youth [Wojtyła-Buciora et al., 2013]. According to a recent survey conducted by the UNICEF in 2013, in Poland the average incidence of obesity in children
TABLE 3. Fatty acids profile of fat extracted from designed bars ( $\mathrm{g} / 100 \mathrm{~g}$ FA).

\begin{tabular}{|c|c|c|c|}
\hline \multicolumn{4}{|c|}{ Bar } \\
\hline FA & Fresh $^{\mathrm{a}}$ & Stored & $p \leq 0.05$ \\
\hline $\mathrm{C} 4: 0$ & $4.21 \pm 0.20$ & $4.59 \pm 0.17$ & $*$ \\
\hline C6:0 & $2.18 \pm 0.10$ & $2.43 \pm 0.16$ & $*$ \\
\hline iso $\mathrm{C} 8: 0$ & $0.03 \pm 0.00$ & $0.00 \pm 0.00$ & \\
\hline $\mathrm{C} 8: 0$ & $1.21 \pm 0.07$ & $1.41 \pm 0.17$ & $*$ \\
\hline $\mathrm{C} 10: 0$ & $2.48 \pm 0.06$ & $2.91 \pm 0.21$ & \\
\hline C11:0 & $0.30 \pm 0.02$ & $0.27 \pm 0.11$ & \\
\hline $\mathrm{C} 12: 0$ & $3.38 \pm 0.27$ & $3.25 \pm 0.15$ & \\
\hline iso $\mathrm{C} 12: 0$ & $0.08 \pm 0.01$ & $0.07 \pm 0.02$ & \\
\hline $\mathrm{C} 13: 0$ & $0.08 \pm 0.00$ & $0.07 \pm 0.01$ & \\
\hline iso $\mathrm{C} 13: 0$ & $0.08 \pm 0.02$ & $0.08 \pm 0.04$ & \\
\hline anteiso $\mathrm{C} 13: 0$ & $0.11 \pm 0.03$ & $0.10 \pm 0.01$ & \\
\hline $\mathrm{C} 14: 0$ & $9.35 \pm 0.21$ & $8.82 \pm 0.31$ & \\
\hline iso $\mathrm{C} 14: 0$ & $0.22 \pm 0.01$ & $0.20 \pm 0.03$ & \\
\hline anteiso $\mathrm{C} 15: 0$ & $0.40 \pm 0.03$ & $0.36 \pm 0.08$ & \\
\hline iso $\mathrm{C} 15: 0$ & $0.91 \pm 0.04$ & $0.82 \pm 0.11$ & \\
\hline $\mathrm{C} 15: 0$ & $0.95 \pm 0.03$ & $0.88 \pm 0.12$ & \\
\hline $\mathrm{C} 15: 1$ & $0.23 \pm 0.05$ & $0.21 \pm 0.07$ & \\
\hline $\mathrm{C} 16: 0$ & $30.45 \pm 1.46$ & $30.07 \pm 1.80$ & \\
\hline iso $\mathrm{C} 16: 0$ & $0.15 \pm 0.02$ & $0.14 \pm 0.05$ & \\
\hline C16:1 n-10 & $0.24 \pm 0.07$ & $0.24 \pm 0.03$ & \\
\hline C16:1 n-7 & $1.26 \pm 0.19$ & $1.19 \pm 0.08$ & \\
\hline anteiso $\mathrm{C} 17: 0$ & $0.35 \pm 0.05$ & $0.32 \pm 0.07$ & \\
\hline iso $\mathrm{C} 17: 0$ & $0.10 \pm 0.01$ & $0.10 \pm 0.02$ & \\
\hline $\mathrm{C} 17: 0$ & $0.47 \pm 0.08$ & $0.46 \pm 0.13$ & \\
\hline $\mathrm{C} 17: 1$ & $0.26 \pm 0.03$ & $0.25 \pm 0.09$ & \\
\hline $\mathrm{C} 18: 0$ & $10.54 \pm 0.29$ & $11.53 \pm 0.15$ & \\
\hline $\mathrm{C} 18: 111 \mathrm{t}$ & $1.40 \pm 0.18$ & $1.43 \pm 0.14$ & \\
\hline VA & $0.78 \pm 0.11$ & $1.18 \pm 0.07$ & \\
\hline $\mathrm{C} 18: 19 \mathrm{c}$ & $21.13 \pm 0.56$ & $20.51 \pm 0.37$ & \\
\hline $\mathrm{C} 18: 111 \mathrm{c}$ & $0.70 \pm 0.14$ & $0.44 \pm 0.11$ & \\
\hline $\mathrm{C} 18: 113 \mathrm{c}$ & $0.15 \pm 0.07$ & $0.00 \pm 0.00$ & \\
\hline $\mathrm{C} 18: 29 \mathrm{c} 12 \mathrm{c}$ & $4.44 \pm 0.31$ & $4.37 \pm 0.25$ & \\
\hline GLA & $0.31 \pm 0.03$ & $0.21 \pm 0.09$ & \\
\hline $\mathrm{C} 18 \mathrm{~s} 39 \mathrm{c} 12 \mathrm{c} 15 \mathrm{c}$ & $0.50 \pm 0.02$ & $0.47 \pm 0.12$ & \\
\hline $\mathrm{C} 20: 0$ & $0.07 \pm 0.01$ & $0.08 \pm 0.01$ & \\
\hline $\mathrm{C} 18: 29 \mathrm{c} 11 \mathrm{t}$ & $0.29 \pm 0.05$ & $0.32 \pm 0.03$ & \\
\hline $\mathrm{C} 21: 0$ & $0.06 \pm 0.00$ & $0.09 \pm 0.02$ & \\
\hline $\mathrm{C} 22: 0$ & $0.08 \pm 0.01$ & $0.09 \pm 0.01$ & \\
\hline $\mathrm{C} 20: 3 \mathrm{n}-3$ & $0.02 \pm 0.00$ & $0.00 \pm 0.00$ & $*$ \\
\hline C20:3 n-6 & $0.03 \pm 0.00$ & $0.00 \pm 0.00$ & $*$ \\
\hline C23:0 & $0.02 \pm 0.01$ & $0.03 \pm 0.00$ & \\
\hline SCSFA & $13.46 \pm 0.91$ & $14.59 \pm 0.29$ & \\
\hline LCSFA & $50.50 \pm 2,39$ & $50.59 \pm 2.51$ & \\
\hline MUFA & $25.66 \pm 1.71$ & $24.99 \pm 0.99$ & \\
\hline PUFA & $5.59 \pm 0.56$ & $5.38 \pm 0.41$ & \\
\hline OBCFA & $4.79 \pm 0.31$ & $4.45 \pm 0.27$ & \\
\hline
\end{tabular}

a Values are expressed as mean \pm SD of results obtained for bar with typical (TS) and reduced (RS) saccharose content. Values with asterisk significantly differ $(p \leq 0.05)$. FA = fatty acid; VA = vaccenic acid; GLA = gamma linolenic acid, SCSFA = short-chained saturated fatty acids, LCSFA $=$ long-chain saturated fatty acids; MUFA = monounsaturated fatty acids, PUFA = polyunsaturated fatty acids, OBCFA = oddand branched-chain fatty acids. 
TABLE 4. Nutritional value of designed bars in comparison to commercial products (per $100 \mathrm{~g}$ of product).

\begin{tabular}{l|c|c|c|c|c}
\hline \multirow{2}{*}{$\begin{array}{l}\text { Sample } \\
\text { code }\end{array}$} & \multicolumn{5}{|c}{ Nutritional value $(100 \mathrm{~g})$} \\
\cline { 2 - 6 } & $\begin{array}{c}\text { Energy } \\
(\mathrm{kcal})\end{array}$ & $\begin{array}{c}\text { Protein } \\
(\mathrm{g})\end{array}$ & $\begin{array}{c}\text { Fat } \\
(\mathrm{g})\end{array}$ & $\begin{array}{c}\text { Monosaccharides } \\
(\mathrm{g})\end{array}$ & $\begin{array}{c}\text { Fiber } \\
(\mathrm{g})\end{array}$ \\
\hline$T S$ & 410 & 6.25 & 17.8 & 38 & 28 \\
$R S$ & 390 & 8.00 & 18.1 & 33.5 & 32.5 \\
\hline C-1 & 400 & 5.6 & 7.0 & 70.4 & 4.25 \\
C-2 & 428 & 4.2 & 14.8 & 68.7 & 2.9 \\
C-3 & 485 & 8.6 & 23.0 & 60.2 & nd \\
C-4 & 452 & 3.7 & 17.0 & 70.3 & nd \\
C-5 & 548 & 9.8 & 33.4 & 50.4 & nd \\
C-6 & 497 & 4.4 & 24.2 & 64.6 & nd \\
C-7 & 533 & 5.2 & 29.2 & 61.5 & nd \\
C-8 & 552 & 8.0 & 34 & 54 & nd \\
C-9 & 535 & 5.4 & 30.5 & 58.5 & nd \\
C-10 & 543 & 8.5 & 32.5 & 54.2 & nd \\
C-11 & 538 & 6.0 & 31.6 & 57.7 & nd \\
C-12 & 414 & 6.5 & 12.8 & 68.3 & nd \\
C-13 & 485 & 4.4 & 23.5 & 63.0 & nd \\
\hline
\end{tabular}

C-1 - C-13 = commercial products; $\mathrm{TS}=$ bar with typical saccharose content; $\mathrm{RS}=$ bar with reduced saccharose content; nd = no data available.

TABLE 5. Quality indicators of designed bars (mean \pm SD).

\begin{tabular}{l|cc}
\hline \multirow{2}{*}{ Parameter } & \multicolumn{2}{|c}{ Bar } \\
\cline { 2 - 3 } & Fresh $^{\mathrm{a}}$ & Stored \\
\hline DPPH (\%) & $23.89 \pm 0.002$ & $23.90 \pm 0.004$ \\
$\mathrm{TPC}(\mathrm{mg} \mathrm{GAE} / 100 \mathrm{~mL}$ extract) & $52.77 \pm 0.351$ & $54.50 \pm 1.646$ \\
$\mathrm{PV}$ (meqO/kg fat) & $1.992 \pm 0.011$ & $1.991 \pm 0.008$ \\
$\mathrm{AnV}$ & $7.517 \pm 0.275$ & $7.823 \pm 0.298$ \\
$\mathrm{AV}$ (mg KOH/g of fat) & $7.258 \pm 0.007$ & $7.287 \pm 0.002$ \\
\hline
\end{tabular}

a Values are expressed as mean \pm SD of results obtained for bar with typical (TS) and reduced (RS) saccharose content. DPPH $=1,1$-diphenyl-2-picrylhydrazyl radical; TPC - total phenolic content; GAE = gallic acid equivalent; $\mathrm{PV}=$ peroxide value; $\mathrm{AnV}=$ anisidine value; $\mathrm{AV}=$ acidic value

reaches 17\% [UNICEF Report, 2013]. In the case of children, therapy of obesity does not involve pharmacological intervention and its treatment should be based on changes in eating habits [Elliott et al., 2004].

Likewise in other countries, also in Poland the main place where the children may purchase food products while staying at school is the school shops. In Poland, the main products bought by children in school shops include: crisps, chocolate bars and sweets [Wojtyła-Buciora et al., 2013]. Surveys conducted among school children and adolescents aged $7-15$ years demonstrated poorer eating patterns with age that resulted from children becoming independent and from the possibility of making self-reliant purchase decisions by pupils. The period of mid-late childhood (7-11 years) is when children are most prone to excessive weight gain [Hughes et al., 2011].

The global strategy for diet, physical activity and health by the WHO recommends the food industry to develop and provide affordable, healthy choices to consumers. Although children have a reasonable understanding of healthy eating, they are less effective in putting this knowledge into practice in order to sustain a healthy eating pattern [Bower \& Sandall, 2002]. To help children make better food choices, healthier snack options should be easily available [Holmer et al., 2012]. Nowadays there is a trend to produce natural, nutritious snacks according with the tendency to reduce consumption of sugary sweets [Estevez et al., 1995]. However nutritive value of snacks for children has been scarcely emphasized.

This research is an attempt of developing "snack" type a food product as a highly-nutritive snack during children's stay at school that could replace fast-foods available in school shops. Bars designed in this study contained substantial amounts of cereal ingredients with a high content of dietary fiber, $\beta$-glucans (oat) and exogenous amino acids (e.g. lysine - amaranth), and characterized by a beneficial composition of the lipid fraction. Considering these ingredients, the designed bars could be appropriate for growing organisms.

The assayed fat content in designed bars was $22 \%$ and was similar to fat content determined in products containing oat and cranberry manufactured in Nordic countries (Denmark and Sweden) [Holmer et al., 2012] while lower in comparison with various bars designed by Estevez et al. [1995], containing different proportions of oat and popped amaranth seed. When comparing the nutritional value of the designed snack bars with commercial products analyzed by Paszczyk et al. [2007], the designed bars are characterized by a considerably lower fat content.

The calculated nutritional value in terms of caloric value was similar to that of products containing oat and cranberry manufactured in Nordic countries [Holmer et al., 2012]. Compared to the analyzed commercial products (Table 4), the nutritional value of the designed bars was distinguished by a higher content of fiber and proteins. The designed bars contained significantly less simple sugars than the commercial products, especially the RS bars, the caloric value of which was significantly lower than that of the commercial products. The package of the designed bars with reduced saccharose content could contain a nutritional claim about reduced caloric value, because accordingly to EU Regulation no. $1924 / 2006$ their caloric value is lower by $30 \%$.

The chromatographic analysis of TAGs composition in fat extracted from the designed bars reflects bars formulation, particularly the presence of milk fat and chocolate (dark) with a high content of cocoa fat (Table 2) [Lipp \& Anklam, 1998]. It is confirmed by quantitative predominance of TAGs : CN52, CN54, CN50, and CN46, in which the main acyls originate from stearic acid C18:0, palmitic acid C16:0 and oleic acid C18:1, as well as by considerable contents of CN 36 and CN34 TAGs - which corresponds with a significant content of FAs belonging to SCSFA group: C8:0 - C14:0, in the analyzed products. The high contribution of milk fat is confirmed mainly by the presence of CN24 - CN28 TAGs, the total content of which reached $1.12 \mathrm{~g} / 100 \mathrm{~g}$ TAG on average. In these TAGs, acyls originated from short- and medium-chain FAs. Such a unique structure of TAGs makes that fat is easily digested by a human body, as SCSFAs in the sn-3 TAG position 
are easily available to pancreatic lipase. The synthesis of fats containing acylglycerols with appropriate FAs at stereospecific positions $s n-1$ and $s n-3$ may lead to the production of lipids capable of preventing hyperlipidemia or obesity [Hanczakowska \& Szewczyk, 2011].

The GC analysis of FAs profile revealed that the designed bars, owing to milk fat contribution in their formulation, contained significant quantities of SCSFAs (14.03 g/ $100 \mathrm{~g}$ FA on average). These acids are known for their very beneficial properties to young organisms [Canani et al., 2011]. They are utilized in the body as an energetic fuel for muscles, heart, liver and kidneys. Their considerable part constitutes a source of energy necessary for metabolic processes, whereas the remaining part is processed into heat further used for $e . g$. maintaining body temperature at a stable level. Because these acids are metabolized without the presence of carnitine, they are not accumulated as storage material and are not risk factors of obesity [Stołyhwo \& Rutkowska, 2013]. In addition, they are very valuable to the development of young organisms as by diffusing to cells of the stomach they activate grelin a hormone which accelerates the growth and development of young organisms both in the prenatal period and after birth [Hanczakowska \& Szewczyk, 2011]. SCSFAs exhibit strong antimycotic and antibacterial effects. Butyric acid, occurring in the designed bars at the level of $4.40 \mathrm{~g} / 100 \mathrm{~g}$ FA, is a potential inhibitor of cells differentiation and apoptosis in many lines of cancer cells. It may inhibit DNA synthesis in cancer cell nuclei and, thereby, prevent their development [Adamska \& Rutkowska, 2014].

Other valuable fatty acids in the lipid fraction of the designed snack bars included CLA, OBCFA, and VA, and their total content reached $5.91 \mathrm{~g} / 100 \mathrm{~g}$ FA. Typical commercial products do not contain these acids [Żbikowska et al., 2015].

The designed bars (fresh and stored) were also assayed for the content of primary and secondary oxidation products, as well as for antioxidant activity and content of phenolic compounds. Worthy of emphasizing are very low levels of lipid oxidation in both fresh bars and these stored for 4 months. The content of FFAs (measured as AV) was high and reached over $7 \mathrm{mg} \mathrm{KOH} / \mathrm{g}$ fat, which resulted from the use of chokeberry fruits in bars formulation that contain significant quantities of organic acids which may, in turn, effect result of determination [Kulling \& Rawel, 2008]. The content of primary oxidation products (PV) was low (even after 4-month storage it did not exceed $2 \mathrm{meq} \mathrm{O} / \mathrm{kg}$ fat) and was 10 times lower than the recommended value for cereals $(20 \mathrm{meq} \mathrm{O} / \mathrm{kg}$ fat) [Estevez et al., 1995]. The content of secondary oxidation products (AnV) increased negligibly during storage (from 7.51 to 7.82), and even though it did not exceed the permissible value $\mathrm{AnV}=8$ stipulated for confectionery products [Aidos et al., 2002]. It also needs to be emphasized that the designed product did not contain any preserving agents. Oxidative stability of the products and their high quality after storage resulted only from the presence of natural bioactive substances with antioxidant properties, including polyphenols from chokeberry - mainly anthocyanins.

The content of polyphenolic compounds in the designed bars ranged from 52.77 to $54.50 \mathrm{mg}$ GAE/ $100 \mathrm{~mL}$ and was higher than in the amaranth and quinoa breads (13.8 and $30.7 \mathrm{mg}$
GAE/100 g, respectively) [Alvarez-Jubete et al., 2010].The high phenolics content may be related to high DPPH ${ }^{\bullet}$ scavenging activity of the designed bars. Free radical scavenging is one of the most important function of antioxidants, since free radicals induce oxidation of lipids, proteins and DNA. This resulted in disturbance and functional loss of biological membranes and enzymes, as well as production of toxic compounds [Niki, 2011]. The antioxidant activity of ethanolic extracts from the designed bars measured as \% of quenched DPPH radical (about 24\%) was higher in comparison with crackers made with refined and wholegrain buckwheat and wheat flours (0.95, 1.63 and $16.2 \%$, respectively) [Sedej et al., 2011].

Sensory evaluation is used in bakery and confectionery companies to assess product quality and to predict consumers' preferences, which is of utmost importance for bakery products, as it determines product development and marketing strategies [Rutkowska \& Żbikowska, 2010]. For product reformulation or improvement, consumer surveys may be needed to confirm that the change in the product is not detrimental to its acceptability [Popper \& Kroll, 2011].

Significant differences $(\mathrm{P} \leq 0.05)$ in hedonic acceptability between types of bars with different contents of sugar were noted (Figure 3) with higher children's preferences for TS bars. However, the acceptability depended on age of the children. Out of the 6 age groups surveyed, this dependency was not observed only in the 9-year-olds, who scored both variants of bars very similarly (Figure 2). Our results confirmed observations of Hausner et al. [2012] that sweetness is considered to be the most important dimension determining children's food preferences. Nordic elementary school children suggested improving the snack bars by making them sweeter [Holmer et al., 2012].

Regardless of the significant differences in the assessments, the overall liking of both types of designed bars was high (4.21 for TS bars and 3.89 for RS bars), similar as in the study conducted among Danish and Swedish children, where the most acceptable type of bar was "oat and cranberry" [Holmer et al., 2012] and slightly lower than cereal bar designed by Estevez et al. [1995].

In children's consumer hedonic evaluation of the product, distribution of individual preferences is also important. More than half of the children scored TS bars as "very tasty" (53\%), whereas RS bars were rated as "very tasty" by approximately $44 \%$ of children (Figure 2). Both variants of bars were evaluated as "tasty" by respectively 22 and $23 \%$ of the children, while only $12 \%$ of the children on average scored their preferences as "very untasty" and "untasty".

Our results are encouraging as they indicate that the quality of diet for children may be improved by providing children with healthy snack products at school shops.

\section{CONCLUSION}

Taking into account the improved nutritional value, safety (very low content of products of lipid oxidation and hydrolysis), and high acceptability among school children, the designed bars may be an interesting confectionery product for children providing an alternative to snacks currently available in school shops. 


\section{ACKNOWLEDGEMENTS}

Research financed under the project "Development of science-development of the region- scholarships and associated support for Mazovia PhD students" co-financed by the European Union under the European Social Fund.

\section{REFERENCES}

1. Adamska A., Rutkowska J., Odd- and branched-chain fatty acids in milk fat - characteristics and health properties. Postępy Hig. Med. Dośw., 2014, 68, 957-966 (in Polish; English abstract).

2. Aidos I., Lourenco S., Van der Padt A., Luten J.B., Boom R.M., Stability of crude herring oil produced from fresh byproducts: Influence of temperature during storage. J. Food Sci., 2002, 67, 3341-3320.

3. Alvarez-Jubete L., Wijngaard H., Arendt E.K., Gallagher E., Polyphenol composition and in vitro antioxidant activity of amaranth, quinoa, buckwheat and wheat as affected by sprouting and baking. Food Chem., 2010, 119, 770-738.

4. AOAC-IUPAC (2000): Method 963.22 Methyl esters of fatty acids in oils and fats. Official Methods of Analysis of A.O.A.C International (17 ${ }^{\text {th }}$ ed.), Association of Official Analytical Chemists, USA.

5. Baryłko-Pikielna N., Matuszewska I., Sensory testing of food. Fundamentals, methods, applications. 2014, PTTŻ, Kraków (in Polish).

6. Bower J.A., Sandall L., Children as consumer - snacking behavior in primary school children. Int. J. Consum. Stud., 2002, 26, 15-26.

7. Brug J., van Stralen M.M., te Velde S.J., Chinapaw M.J.M., De Bourdeauhuij I., Lien N., Bere E., Maskini V., Singh A.S., Maes L., Moreno L., Jan N., Kovacs E., Lobstein T., Manios Y., Differences in weight status and energy-balance related behaviors among schoolchildren across Europe: The Energy-Project. Plos One, 2012, 7, 71-13.

8. Canani R.B., Costanzo M.D., Leone L., Bedogni G., Brambilla P., Cianfarani S., Nobili V., Pietrobelli A., Agostoni C., Epigenetic mechanisms elicited by nutrition in early life. Nutr. Res. Rev., 2011, 24, 198-205.

9. Cunningham S.A., Kramer M.R., Venkat Narayan K.M., Incidence of childhood obesity in the United States. N. Engl. J. Med., 2014, 370, 403-411.

10. de Onis M., Blössner M., Borghi E., Global prevalence and trends of overweight and obesity among preschool children. Am. J. Clin. Nutr., 2010, 92, 1257-64.

11. Elliott C., Assessing 'fun foods': nutritional content and analysis of supermarket foods targeted at children. Obes. Rev., 2008, 9 , 368-377.

12. Elliott M.A., Copperman N.M., Jacobson M.S., Pediatric obesity prevention and management. Minerva Pediatr., 2004, 56, 265-276.

13. Estevez A.M., Escobar B., Vasquez M., Castillo E., Araya E., Zacarias I., Cereal and nut bars, nutritional quality and storage stability. Plant Foods Hum. Nutr., 1995, 47, 309-317.

14. Ferrazzano G.F., Amato I., Ingenito A., Zarrelli A., Pinto G., Pollio A., Plant polyphenols and their anti-cariogenic properties: a review. Molecules, 2011, 16, 1486-1507.

15. Hanczakowska E., Szewczyk A., Short- and medium-chain fatty acids in piglet feeding. Roczn. Nauk. Zoot., 2011, 38, 3-10 (in Polish; English abstract).
16. Haslam D.W., James W.P., Obesity. Lancet, 2005, 366, $1197-$ $-1209$.

17. Hausner H., Hartvig D.L., Reinbach H.C., Wendin K., Bredie W.L.P., Effect of repeated exposure on acceptance of initially disliked and liked Nordic snack bars in $9-11$ year old children. Clin. Nutr., 2012, 31, 137-143.

18. Hedley A.A., Ogden C.L., Johnson C.L., Prevalence of overweight and obesity among US children, adolescents, and adults, 1999-2002. JAMA, 2004, 291, 2847-2850.

19. Holmer A., Hausner H., Reinbach H.C., Bredie W.L.P., Wendin K., Acceptance of Nordic snack bars in children aged 8-11 years. Food Nutr. Res., 2012, 56, 10848-10855.

20. Hughes A.R., Sheriff A., Lawlor D.A., Ness A.R., Reilly J.J., Incidence of obesity during childhood and adolescence in a large contemporary cohort. Prev. Med., 2011, 52, 300-304.

21. ISO 2008. Method 6885. Edible vegetable fats. Determination of anisidine value. International Organization for Standarization: Geneva, Switzerland.

22. ISO 2010. Method 660. Animal and vegetable fats and oils. Determination of acid value and acidity. International Organization for Standarization: Geneva, Switzerland.

23. ISO 2012. Method 3960. Animal and vegetable fats and oils. Determination of peroxide value. International Organization for Standarization: Geneva, Switzerland.

24. Kulling S.E., Rawel H.M., Chokeberry (Aronia melanocarpa) A review on the characteristic components and potential health effects. Planta Med., 2008, 74, 1625-1634.

25. Kunachowicz H., Nadolna I., Przygoda B., Iwanow K., Food composition and nutritional tables. 2005, PZWL, Warszawa (in Polish).

26. Lakshman R., Elks C.E., Ong K.K., Childhood obesity. Circulation, 2012, 126, 1770-1779.

27. Lipp M., Anklam E., Review of cocoa butter and alternative fats for use in chocolate - Part A. Compositional data. Food Chem., 1998, 62, 73-97.

28. Mills S., Ross R.P., Hill C., Fitzgerald G.F., Stanton C., Milk intelligence: Mining milk for bioactive substances associated with human health. Int. Dairy J., 2011, 21, 377-401.

29. Mlakar S.G., Turinek M., Jakop M., Bavec M., Bavec F., Nutrition value and use of grain amaranth: potential future application in bread making. Agricultura, 2009, 6, 43-53.

30. Mozaffarian D., Aro A., Willett W.C., Health effects of trans-fatty acids: experimental and observational evidence. Eur. J. Clin. Nutr., 2009, 63, S5-S21.

31. Niki E., Antioxidant capacity: which capacity and how to assess it? J. Berry Res., 2011, 1, 169-176.

32. Paszczyk B., Żegarska Z., Borejszo Z., Composition of fatty acids and trans isomers of fatty acids of selected confectionery products. Żywność. Nauka. Technologia. Jakość, 2007, 53, 55-65 (in Polish; English abstract).

33. Polish Standard PN-EN ISO 5508:2000. Vegetable oils and animal fats. Analysis of fatty acid methyl esters by gas chromatography.

34. Polish Standard PN-71/A-88021:1971P. Confectionery products. Determination of fat content.

35. Popper R., Kroll J.J., Consumer testing of food products using children. 2011, in: Developing Children's Food Products (eds. D. Kilcast, F. Angus). Woodhead Publishing Series, pp. 163$-187$. 
36. Regulation (EC) No 1924/2006 of the European Parliament and of the Council of 20 December 2006 on nutrition and health claims made on foods.

37. Rutkowska J., Adamska A., Białek M., Fatty acid profile of the milk of cows reared in the mountain region of Poland. J. Dairy Res., 2012, 79, 469-476.

38. Rutkowska J., Żbikowska A., Effects of fatty acids composition of liquid margarines on sensory quality of cakes. Acta Alimentaria, 2010, 39, 136-148.

39. Sanchez-Moreno C., Larrauri J.A., Saura-Calixto F., A procedure to measure the antiradical efficiency of polyphenols. J. Sci. Food Agric., 1998, 76, 270-276.

40. Sedej I., Sakac M., Mannic A., Misan A., Pestoric M., Simurina O., Canadanovic-Brunet J., Quality assessment of gluten-free crackers based on buckwheat flour. LWT - Food Sci. Technol., 2011, 44, SI, 694-699.

41. Sikorska-Wiśniewska G., Overweight and obesity in children and young people. Żywność, Nauka. Technologia. Jakość, 2007, 55, 71-80 (in Polish; English abstract).

42. Singleton V.L., Rossi J.A., Colorimetry of total phenolics with phosphomolybdic - phosphotungstic acid reagents. Am. J. Enol. Vitic., 1965, 16, 144-158.

43. Stołyhwo A., Rutkowska J., Milk fat: structure, composition and health benefits. 2013, in: Food Chemistry, vol. 3 (ed. Z.E. Sikorski). WNT, Warszawa, pp. 39-88 (in Polish).

44. UNICEF Office of Research: Child well-being in rich countries. A comparative overview. Innocenti Report Card 11, Unicef Office of Research, Florence, 2013.
45. Wojtyła-Buciora P., Stawińska-Witoszyńska B., Klimberg A., Wojtyła A., Goździewska M., Wojtyła K., Piątek J., Wojtyła C., Sygit M., Ignyś I., Marcinkowski J.T., Nutrition-related health behaviours and prevalence of overweight and obesity among Polish children and adolescents. Ann. Agric. Environ. Med., 2013, $20,332-340$.

46. Wolnicka K., Taraszewska A., Jaczewska-Schuetz J., Prevalence of overweight, obesity and underweight among 3rd grade students of primary schools taking into account regional differences. Endocrin. Obesity Met. Disor., 2012, 8, 80-8.

47. Wood P.J., Cereal $\beta$-glucans in diet and health. J. Cereal Sci., 2007, 46, 230-238.

48. World Health Organisation, Social determinants of health and well-being among young children. Health behavior in school-age children (HBSC) study. International Report from the 2009/2010 survey.

49. World Health Organisation. European Childhood Obesity Surveillance Initiative, COSI, 2010.

50. World Health Organisation: Report of Consultation on Obesity. Obesity. Preventing and managing the global epidemic. Geneva, 3-5 June 1997.

51. Żbikowska A, Rutkowska J, Kowalska M., Consumption safety of pastries, confectionery and potato products as related to fat content. J.Am. Coll. Nutr., 2015, DOI: 10.1080/07315724.2014.942472.

Submitted: 27 October 2014. Revised: 11 March 2015. Accepted: 8 April 2015. Published on-line: 21 October 2015. 